\title{
Electrochemical Impedance study of Proton Conducting Polymer Electrolytes based on PVC Doped with Thiocyanate and Plasticized with Glycerol
}

\author{
Jihad M. Hadi ${ }^{1,2}$, Shujahadeen B. Aziz ${ }^{3,4^{*}}$, Muhammad S. Mustafa ${ }^{5}$, M. A. Brza ${ }^{3}$,

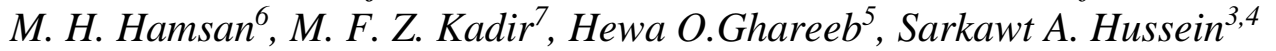 \\ ${ }^{1}$ Kurdistan Technical Institute,Sulaimani, Kurdistan Regional Government-Iraq \\ ${ }^{2}$ College of Engineering, Tishk International University, Sulaimani, Kurdistan Regional Government- \\ Iraq \\ ${ }^{3}$ Hameed majid Advanced Polymeric Materials Research Lab., Department of Physics, College of \\ Science, University of Sulaimani, Qlyasan Street, Sulaimani, Kurdistan Regional Government-Iraq \\ ${ }^{4}$ Department of Civil Engineering, College of Engineering, Komar University of Science and \\ Technology, Sulaimani, 46001, Kurdistan Regional Government, Iraq \\ ${ }^{5}$ Department of Chemistry, College of Science, University of Sulaimani, Qlyasan Street, Sulaimani, \\ Kurdistan Regional Government-Iraq \\ ${ }^{6}$ Institute for Advanced Studies, University of Malaya, 50603 Kuala Lumpur, Malaysia \\ ${ }^{7}$ Centre for Foundation Studies in Science, University of Malaya, 50603 Kuala Lumpur, Malaysia \\ *E-mail: shujahadeenaziz@gmail.com;shujaadeen78@yahoo.com
}

doi: $10.20964 / 2020.05 .34$

Received: 1 February 2020/ Accepted: 12 March 2020 / Published: 10 April 2020

Solid polymer electrolyte (SPE) system based on poly (vinyl chloride) PVC doped with ammonium thiocyanate $\left(\mathrm{NH}_{4} \mathrm{SCN}\right)$ salt has been prepared by solution cast techniques using glycerol as a plasticizer and THF tetra-hydro furan as a solvent. To examine the electrical properties of the electrolyte films the electrochemical impedance spectroscopy (EIS) has been used. The effect of glycerol on electrical properties and structure of the plasticized PVC-based polymer electrolyte was examined, and the various weight ratio of glycerol plasticizer $(\% 5, \% 10, \% 15$, and \% 20) of PVC$\mathrm{NH}_{4} \mathrm{SCN}$ weight is well correlated. Electrolytes are the heart of electrochemical devices and their conductivity investigation is crucial from the viewpoint of electrochemical device application. EIS electrode impedance spectroscopy was used to determine the bulk resistance $\mathrm{Rb}$ of the films at room temperature. The increase of the ionic conductivity with an increase in the amount of glycerol was observed through an impedance study, and the maximum ionic conductivity was $1.02512 \times 10^{-6} \mathrm{~S} \mathrm{~cm}^{-1}$ obtained from (PVC-\%20 NH 4 SCN-\%20 glycerol) system. Dielectric relaxation studies of the polymer electrolyte film have been studied. The rise of the dielectric polarization of the films is proved by increases in a dielectric constant and dielectric loss. The peaks appeared in the imaginary part of the electric modulus reveals that ion conduction occurs through the viscoelastic relaxation dynamic. In the AC conductivity pattern plateau region ascribed to DC conductivity is appeared. 
Keywords: PVC electrolyte; NH4SCN; plasticizer; impedance study; dielectric properties

\section{FULL TEXT}

(C) 2020 The Authors. Published by ESG (www.electrochemsci.org). This article is an open access article distributed under the terms and conditions of the Creative Commons Attribution license (http://creativecommons.org/licenses/by/4.0/). 